\title{
New particle formation in forests inhibited by isoprene emissions
}

\author{
Jürgen Wildt (1), Astrid Kiendler-Scharr (2), Miikka Dal Maso (1,3), Thorsten Hohaus (2), Einhard Kleist (1), \\ Thomas F. Mentel (2), Ralf Tillmann (2), Ricarda Uerlings (1), and Andreas Wahner (2) \\ (1) Forschungszentrum Jülich, ICG-3: Phytosphäre, Jülich, Germany (j.wildt@fz-juelich.de), (2) Forschungszentrum Jülich, \\ ICG-2: Troposphäre, Jülich, Germany, (3) Department of Physics, University of Helsinki, 00014 Hesinki, Finland
}

Biogenic volatile organic compounds (BVOC) are involved in organic aerosol formation, which in turn affects radiative forcing, cloud formation and climate. Many laboratory experiments have shown that secondary organic aerosols (SOA) are efficiently produced from oxidation of sesqui- and monoterpenes. However, the most abundant BVOC emitted from vegetation is isoprene and the contribution of isoprene to formation of new aerosols is highly uncertain.

We measured the impact of isoprene on SOA formation in the Juelich plant atmosphere chamber (JPAC) under controlled conditions. BVOC emitted from plants in a plant chamber were fed into a reaction chamber where they were oxidized by ozone and by $\mathrm{OH}$ radicals. Spruce, pine, birch and beech were used as BVOC sources as they emit only low amounts of isoprene. This allowed investigating the impacts of isoprene on SOA formation by adding it to the realistic mix in the reaction chamber.

In the presence of $60 \mathrm{ppb}$ ozone SOA formation was not observable up to BVOC concentrations of $100 \mathrm{ppbC}$. Production of $\mathrm{OH}$ radicals by ozone photolysis induced strong SOA formation events with nucleation rates up to several hundred cm-3 s-1. Keeping the BVOC emissions from the plants constant and adding isoprene led to an efficient reduction of SOA formation. With increasing isoprene concentrations nucleation rates decreased down to zero.

We found evidence that the inhibition of nucleation by isoprene was caused by a reduction of $\mathrm{OH}$ concentrations in the reaction chamber. Analysis of nucleation rates in dependence on $\mathrm{OH}$ concentration indicated a power law dependence of 3-4 implying that it takes 3-4 oxidation steps to form SOA from the given mixtures. This high power law dependence as well as the high reactivity of isoprene versus $\mathrm{OH}$ caused the high efficiency of inhibition. We conclude that if in the future the relative isoprene abundance of biogenic VOC emissions increases in response to climate change or land use change, the new particle formation potential may decrease, thus damping the aerosol negative radiative forcing effect. 